\title{
Anatomic Double-Bundle Anterior Cruciate Ligament Reconstruction Using an Outside-in Technique: Two- to Six-Year Clinical and Radiological Follow-up
}

\author{
Jae Ang Sim, $\mathrm{MD}^{1}$, Yong Seuk Lee, $\mathrm{MD}^{2}$, Kyung Ok Kim, $\mathrm{PhD}^{3}$, Jong Keun Kim, $\mathrm{MD}^{1}$, and Beom Koo Lee, $\mathrm{MD}^{1}$ \\ ${ }^{1}$ Department of Orthopaedic Surgery, Gil Hospital, Gachon University of Medicine and Science, Incheon; ${ }^{2}$ Department of Orthopaedic Surgery, Seoul National \\ University Bundang Hospital, Bundang; ${ }^{3}$ Gachon Medical Research Institute, Gil Hospital, Gachon University of Medicine and Science, Incheon, Korea
}

\begin{abstract}
Purpose: We evaluated the clinical and radiological outcomes of double-bundle anterior cruciate ligament (ACL) reconstruction using an outside-in technique with a follow-up of two- to six-years, especially in terms of the sports activity level and radiological degeneration.

Materials and Methods: Sixty-seven patients who were available for a minimum two-year follow-up after double-bundle ACL reconstruction using an outside-in technique were retrospectively evaluated. The mean follow-up period was 43.7 months. The knee function and stability were evaluated before the operation, one year after the operation (short-term follow-up), and more than two years after the operation (last follow-up).

Results: Regarding the knee function, the Lysholm score, International Knee Documentation Committee (IKDC) evaluation, and hop test showed significant improvement. Regarding the stability, the Lachman test, pivot shift test, KT-2000 arthrometer data, and anterior drawer radiographs using Telos showed significant improvement. Regarding the sports activity level, the patients who returned to pre-injury level activity was $68.7 \%$ according to the Tegner activity score and $76.1 \%$ according to the Cincinnati sports activity scale score. The incidence of aggravated degeneration or development of greater than IKDC grade A degeneration after surgery was $10.4 \%$.

Conclusions: Double-bundle ACL reconstruction using an outside-in technique showed favorable clinical and radiological outcomes with respect to the knee function and stability, joint degeneraion, and, especially, return to pre-injury sports activity.
\end{abstract}

Keywords: Anterior cruciate ligament, Reconstruction, Double bundle, Outside-in technique

\section{Introduction}

The goals of anterior cruciate ligament (ACL) reconstruction are the relief of symptoms, improvement of function, and return to pre-injury sports activity ${ }^{1)}$. According to a recent meta-analysis, $63 \%-75 \%$ of patients returned to pre-injury sports activity

Received May 21, 2014; Revised (1st) September 21, 2014;

(2nd) December 13, 2014; (3rd) January 7, 2015;

Accepted January 15, 2015

Correspondence to: Beom Koo Lee, MD

Department of Orthopaedic Surgery, Gil Hospital, Gachon University 21

Namdong-daero 774beon-gil, Namdong-gu, Incheon 405-760, Korea

Tel: +82-32-460-3384, Fax: +82-32-468-5437

E-mail: bklee@gilhospital.com

This is an Open Access article distributed under the terms of the Creative Commons Attribution Non-Commercial License (http://creativecommons.org/licenses/by-nc/3.0/) which permits unrestricted non-commercial use, distribution, and reproduction in any medium, provided the original work is properly cited. and only $44 \%$ of patients were able to perform competitive sports activity $^{2)}$. However, in the study, many surgical procedures were mixed up and it was difficult to determine which method was better to accomplish the goals of ACL reconstruction. The midterm follow-up of non-anatomical single-bundle ACL reconstruction showed relatively satisfactory clinical results; however, the incidences of return to sports activity were relatively low ${ }^{3-7)}$.

Many researchers have reported that non-anatomical singlebundle ACL reconstruction caused degenerative arthritic changes because normal knee kinematics was not recovered ${ }^{6,8-11)}$. Recent techniques for ACL reconstructions focus on the restoration of anatomic double-bundle with the goal of better replicating the anatomy of the native ACL ${ }^{12-14)}$. Some studies have reported similar or superior results of double-bundle ACL reconstruction compared to those of single-bundle ACL reconstruction. These strategies are also supported by evidence showing that superior clinical outcomes occur when graft placement is aligned with the 
native $\mathrm{ACL}^{14-16)}$.

The purpose of this study was to evaluate the clinical and radiological outcomes of double-bundle ACL reconstruction using an outside-in technique with a follow-up of two- to six-years, especially from the standpoint of sports activity and radiological degeneration. The hypothesis of this study was that double-bundle ACL reconstruction using an outside-in technique would show favorable results in terms of clinical outcomes and degenerative changes.

\section{Materials and Methods}

\section{Demographics}

From 2004 to 2010, 67 patients who underwent double-bundle ACL reconstruction using an outside-in technique were enrolled in this retrospective study. Patients who had multiple ligamentous injury (combined posterior cruciate ligament injury or at least three ligamentous injuries), moderate or severe cartilage damage, history of cartilage repair procedure, and ACL revision reconstruction were excluded. Fifty-nine patients were male and eight patients were female. Their average age was 29.6 years (range, 15 to 56 years). The mean time from injury to surgery was 7.2 months (range, 0.25 to 96 months) and the mean followup period was 43.7 months (range, 24.5 to 76.9 months). The mean body mass index was $25.9 \mathrm{~kg} / \mathrm{m}^{2}$ (range, 18.7 to $36.0 \mathrm{~kg} / \mathrm{m}^{2}$ ). Institutional Review Board approval was obtained prior to initiation of the study.

\section{Accompanying Injuries}

There were 11 medial collateral ligament injuries. Conservative treatment was performed in 5 cases and repair was done in 6 cases. Four lateral collateral ligamentous injuries were treated by conservative treatment in 1 case, repair in 2 cases, and aug- mentation in 1 case, respectively. When patients had conservative treatment for concomitant collateral ligamentous injury, delayed ACL reconstruction was performed after obtaining full range of motion. Repair or augmentation was simultaneously performed with ACL reconstruction.

Twenty-six medial meniscus tears and 16 lateral meniscus tears were combined with ACL injury. The medial meniscus tears were treated with conservative treatment in 4 cases, repair in 8 cases, partial meniscectomy in 8 cases, subtotal meniscectomy in 5 cases, and total meniscectomy in 1 case. The lateral meniscus tears were treated with conservative treatment in 2 cases, repair in 4 cases, partial meniscectomy in 8 cases, subtotal meniscectomy in 1 case, and total meniscectomy in 1 case. In the case of concomitant meniscal operation, ACL reconstruction was performed simultaneously.

There was one non-displaced patella fracture treated by screw fixation combined with ACL reconstruction.

\section{Surgical Technique and Rehabilitation}

Three-strand semitendinosus tendon was used for anteromedial (AM) bundle graft (mean diameter, $8 \mathrm{~mm}$; range, 8 to $10 \mathrm{~cm}$ ) and four-strand gracilis tendon extended by 2 Mersilene tape (Ethicon Inc., Somerville, NJ, USA) was used for posterolateral (PL) bundle graft (mean diameter, $7 \mathrm{~mm}$; range, 5 to $7 \mathrm{~cm})^{17,18}$. The two types of grafts underwent pre-tensioning until ACL reconstruction.

The centers of femoral tunnels were placed in those of ACL stump or fossae divided by lateral intercondylar ridge and bifurcate ridge $^{6)}$ (Fig. 1). Unless two osseous landmarks were distinctly shown, the center of the AM bundle tunnel was located at $6 \mathrm{~mm}$ distal from the back wall of the femur, and that of the PL bundle tunnel was positioned at $5 \mathrm{~mm}$ anterior to the edge of the joint cartilage on the vertical line at $90^{\circ}$ of flexion ${ }^{14)}$. The centers of tibial
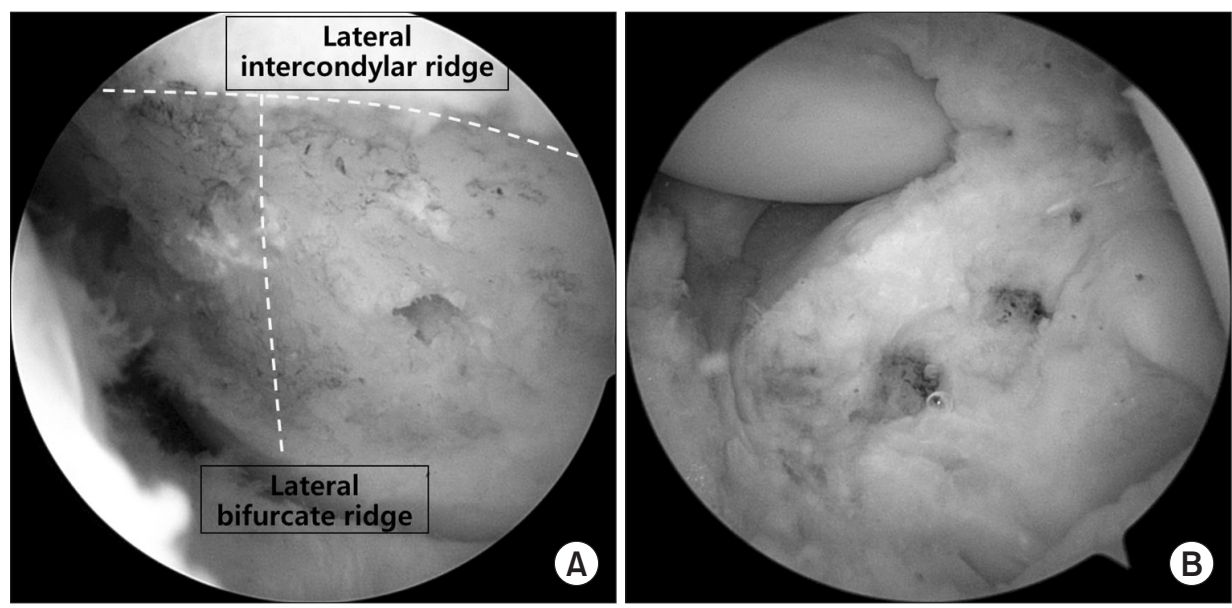

Fig. 1. The centers of femoral (A) and tibial (B) tunnels. 
tunnels were also placed in those of the ACL stump (Fig. 1). When there was no stump, the center of the PL bundle tunnel was located at the center or slightly lateral between two tibial eminences or on the extended line 2 to $3 \mathrm{~mm}$ anterior to the posterior margin of the lateral meniscus insertion, and that of the AM bundle tunnel was positioned at $8 \mathrm{~mm}$ anterior to the center of the PL bundle tunnel or on the extended line slightly lateral to the medial tibial eminence.

After insertion of guide pins, we checked the position of the tunnel centers on the lateral view using an image intensifier. Both tibial and femoral tunnels were made by an outside-in technique and reamed according to the diameter of grafts, respectively. In order to prevent mismatch between the diameter of the graft and that of the tunnel, grafts were inserted from the larger side to the smaller side. Femoral fixation was performed using the Ligament Plate (Solco Biomedical Co., Seoul, Korea) and tibial fixation was performed by two post-tie using 5-0 Etibond (Ethicon Inc.) in $15^{\circ}$ of flexion ${ }^{17,18)}$.

The knee was immobilized in full extension immediately postoperatively. Full passive range of motion and straight leg raising exercise were permitted two days after surgery. For patients who underwent meniscal repair, partial weight bearing was allowed only for eight weeks, the other patients who did not undergo meniscal repair tried full weight bearing as tolerated and closed chain exercise immediately after surgery. All patients wore a brace for 12 weeks after the operation. When the patient did not feel instability anymore and the pivot shift test was negative and hop test recovered more than $85 \%$ of that of the contralateral normal knee, light exercise such as jogging was allowed for six months after surgery. Strenuous sports such as soccer were allowed 12 months after the operation.

\section{Evaluations}

Patients were evaluated before the operation, one year after the operation (short-term follow-up), and more than two years after the operation (last follow-up).

\section{1) Clinical evaluation}

For functional outcome assessment, the Lysholm score, International Knee Documentation Committee (IKDC) evaluation ${ }^{19)}$, range of motion measurement, the difference of mid-thigh circumference measured at $10 \mathrm{~cm}$ above the upper pole of the patella compared to the contralateral side, and hop test were used. For the stability testing, the Lachman test, pivot shift test, KT2000 arthrometer testing, and anterior drawer radiographs using Telos (Telos, Weterstadt, Germany) were performed.
2) Radiological evaluation of degenerative changes

The standing anteroposterior view and standing tunnel view were used for evaluation of degenerative changes in the medial and lateral compartments of the femorotibial joint. The Merchant view was used for evaluation of degenerative changes in the patellofemoral joint. Degenerative arthritic changes were evaluated and categorized into four groups according to the IKDC recommendations: A (normal), B (minimal changes and barely detectable joint space narrowing), $\mathrm{C}$ (minimal changes and joint space narrowing up to 50\%), and D (more than 50\% joint space narrowing). In this study, IKDC grade $\mathrm{B}, \mathrm{C}$, and $\mathrm{D}$ were regarded as degenerative arthritic changes. In addition, we also compared the occurrence of degeneration between groups divided according to age (younger than 43.1 years vs. older than 43.1 years), time from injury to surgery (less than one month vs. more than one month), existence of accompanying ligament injuries, and treatment of meniscus injuries (repair, partial meniscectomy, subtotal meniscectomy, or total meniscectomy).

3) Sports activity evaluation

The Tegner activity score ${ }^{20)}$ and Cincinnati sports activity scale score $^{21)}$ were used in the evaluation of sports activity. Return to pre-injury sports activity was considered obtained if the postoperative sports activity scores were the same as those of the preinjury sports activity.

\section{Statistics Analysis}

SPSS ver. 12.0 (SPSS Inc., Chicago, IL, USA) was used for the analysis of the data. The range of motion, the difference of midthigh circumference, hop test results, KT-2000 arthrometer data, and anterior drawer radiographs were analyzed by paired t-test. The Lysholm score, IKDC objective grade, Lachman test, pivot shift test, Tegner activity score, and Cincinnati sports activity scale score were analyzed by Wilcoxon signed ranks test. Fisher's exact test was performed in order to determine the relationship between development of degenerative changes and factors. A pvalue less than 0.05 was considered statistically significant.

\section{Results}

\section{Clinical Results}

In terms of the functional outcome, the Lysholm score and IKDC objective grade showed significant improvement at the short-term and last follow-ups compared to the preoperative level (Table 1). No significant difference was observed between the short-term and the last follow-up Lysholm score and IKDC 
objective grade. The range of motion and the difference of midthigh circumference compared to the contralateral side were slightly improved at the short-term and the last follow-ups compared to the preoperative values, but the difference was not statistically significant (Table 1). Hop test results showed significant improvement at the last follow-up compared to the short-term follow-up (Table 1).

With regard to the stability, the Lachman test, pivot shift test, KT-2000 arthrometer testing, and $30^{\circ}$ and $90^{\circ}$ anterior drawer radiographs using Telos showed significant improvement at the short-term and last follow-ups compared to the preoperative values, and no significant difference was observed between the short-term and last follow-up results (Table 2).

\section{Radiological Degenerative Changes}

There were 5 patients (7.5\%) with preoperative degenerative arthritic changes (Table 3). Among them, 1 patient did not show any difference between the short-term and the last follow-up period. The other 4 patients (6.0\%) showed aggravation. In three patients (4.5\%) who had no preoperative degenerative arthritic changes, newly developed degenerative changes were observed at the last follow-up (Fig. 2). Among them, degenerative changes occurred since the short-term follow-up in 2 patients. Therefore, 7 patients (10.4\%) had aggravated or newly developed degeneration (greater than IKDC grade A) at the last follow-up. There were 3 patients with IKDC grade B and 4 patients with IKDC grade $\mathrm{C}$ (Table 3 ).

On comparison of degeneration between groups, 6 of 26 pa-

Table 1. Functional Evaluation

\begin{tabular}{|c|c|c|c|c|c|c|}
\hline \multirow{2}{*}{ Variable } & \multirow{2}{*}{ Preoperative (A) } & \multirow{2}{*}{ Short-term follow-up (B) } & \multirow{2}{*}{ Last follow-up (C) } & \multicolumn{3}{|c|}{ p-value ${ }^{\mathrm{a})}$} \\
\hline & & & & $\mathrm{A}$ and $\mathrm{B}$ & $\mathrm{A}$ and $\mathrm{C}$ & $\mathrm{B}$ and $\mathrm{C}$ \\
\hline $\begin{array}{l}\text { Lysholm score (point), } \\
\text { median (range) }\end{array}$ & $70(30-90)$ & $94(49-100)^{\mathrm{b})}$ & $95(64-100)^{b)}$ & 0.001 & 0.001 & 0.531 \\
\hline IKDC category, no. (\%) & $\begin{array}{c}\mathrm{B}, 18 \text { (26.9); C, } 32(47.8) ; \\
\mathrm{D}, 17(25.4)\end{array}$ & $\begin{array}{c}\text { A, } 40(59.7) ; B, 17(25.4) ; \\
\text { C, } 10(14.9)^{\text {b) }}\end{array}$ & $\begin{array}{c}\text { A, } 46(68.7) ; \mathrm{B}, 16(23.9) ; \\
\text { C, } 5(7.5)^{\mathrm{b})}\end{array}$ & $<0.001$ & $<0.001$ & 0.075 \\
\hline $\begin{array}{l}\text { Range of motion }\left({ }^{\circ}\right), \\
\text { mean } \pm \text { SD }\end{array}$ & $115.4 \pm 16.2$ & $133.1 \pm 6.0$ & $135.6 \pm 5.7$ & 0.500 & 0.108 & 0.356 \\
\hline $\begin{array}{l}\text { The difference of mid-thigh } \\
\text { circumference }(\mathrm{cm}) \text {, mean } \pm S D\end{array}$ & $1.8 \pm 1.8$ & $1.2 \pm 1.3$ & $0.7 \pm 1.0^{c)}$ & 0.593 & 0.197 & 0.005 \\
\hline Hop test (\%), mean \pm SD & - & $88.4 \pm 16.9$ & $98.0 \pm 5.3^{c)}$ & - & - & $<0.001$ \\
\hline
\end{tabular}

IKDC: International Knee Documentation Committee, SD: standard deviation.

${ }^{\text {a) }}$ Paired t-test and Wilcoxon signed ranks test.

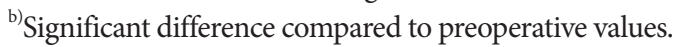

${ }^{c}$ Significant difference compared to short-term follow-up values.

Table 2. Stability Assessment

\begin{tabular}{|c|c|c|c|c|c|c|}
\hline \multirow{2}{*}{ Variable } & \multirow{2}{*}{ Preoperative (A) } & \multirow{2}{*}{ Short-term follow-up (B) } & \multirow{2}{*}{ Last follow-up $(\mathrm{C})^{\mathrm{a})}$} & \multicolumn{3}{|c|}{ p-value ${ }^{\text {b) }}$} \\
\hline & & & & $\mathrm{A}$ and $\mathrm{B}$ & $\mathrm{A}$ and $\mathrm{C}$ & $\mathrm{B}$ and $\mathrm{C}$ \\
\hline Lachman test & $\begin{array}{c}+++, 13(19.4) ; \\
++, 18(26.9) ;+, 36(53.7)\end{array}$ & $\begin{array}{c}++, 3(4.5) ;+ \\
5(7.5) ;-, 59(88.1)\end{array}$ & $\begin{array}{c}++, 2(3.0) ;+ \\
4(6.0) ;-, 61(91.0)\end{array}$ & $<0.001$ & $<0.001$ & 0.157 \\
\hline Pivot shift test & $\begin{array}{l}+++, 9(13.4) ;++, 15(22.4) \\
\quad+, 27(40.0) ;-, 16(23.9)\end{array}$ & $\begin{array}{c}++, 1(1.5) ;+ \\
8(11.9) ;-, 58(86.6)\end{array}$ & $\begin{array}{c}++, 1(1.5) ;+ \\
5(7.5) ;-, 61(91.0)\end{array}$ & $<0.001$ & $<0.001$ & 0.083 \\
\hline KT-2000 arthrometer (mm) & $3.7 \pm 2.2$ & $1.2 \pm 1.2$ & $1.0 \pm 1.4$ & 0.001 & 0.004 & 0.527 \\
\hline $\begin{array}{l}30^{\circ} \text { anterior drawer } \\
\text { radiographs }(\mathrm{mm})\end{array}$ & $4.6 \pm 3.0$ & $1.1 \pm 2.0$ & $1.2 \pm 2.1$ & $<0.001$ & $<0.001$ & 0.822 \\
\hline $\begin{array}{l}90^{\circ} \text { anterior drawer } \\
\text { radiographs }(\mathrm{mm})\end{array}$ & $4.5 \pm 3.1$ & $0.9 \pm 2.8$ & $0.9 \pm 2.8$ & $<0.001$ & $<0.001$ & 0.684 \\
\hline
\end{tabular}

Values are presented as number (\%) or mean \pm standard deviation.

${ }^{a}$ Significant difference compared to preoperative values.

${ }^{b)}$ Paired t-test and Wilcoxon signed ranks test. 
Table 3. Arthritic Changes Evaluated According to International Knee Documentation Committee Recommendations

\begin{tabular}{|c|c|c|c|c|c|c|c|c|c|}
\hline \multirow{2}{*}{ Case } & \multicolumn{3}{|c|}{ Preoperative } & \multicolumn{3}{|c|}{ Short-term follow-up } & \multicolumn{3}{|c|}{ Last follow-up } \\
\hline & Patello-femoral & Medial & Lateral & Patello-femoral & Medial & Lateral & Patello-femoral & Medial & Lateral \\
\hline 1 & B & B & A & B & $\mathrm{C}$ & A & B & $\mathrm{C}$ & A \\
\hline 2 & A & A & $\mathrm{B}$ & A & $\mathrm{B}$ & B & A & B & $\mathrm{C}$ \\
\hline 3 & $\mathrm{~A}$ & B & A & $\mathrm{A}$ & $\mathrm{C}$ & A & A & $\mathrm{C}$ & A \\
\hline 4 & $\mathrm{~B}$ & B & A & $\mathrm{B}$ & $\mathrm{C}$ & B & B & $\mathrm{C}$ & B \\
\hline 5 & B & B & A & B & B & A & B & B & A \\
\hline 6 & $\mathrm{~A}$ & $\mathrm{~A}$ & A & A & A & B & A & A & B \\
\hline 7 & A & A & A & A & B & B & A & B & B \\
\hline 8 & $\mathrm{~A}$ & $\mathrm{~A}$ & $\mathrm{~A}$ & $\mathrm{~A}$ & A & $\mathrm{A}$ & $\mathrm{A}$ & $\mathrm{B}$ & $\mathrm{A}$ \\
\hline
\end{tabular}

Grade B and C indicate arthritic changes.

A: normal, B: minimal changes and barely detectable joint space narrowing, C: minimal changes and joint space narrowing up to $50 \%$, D: more than $50 \%$ joint space narrowing.
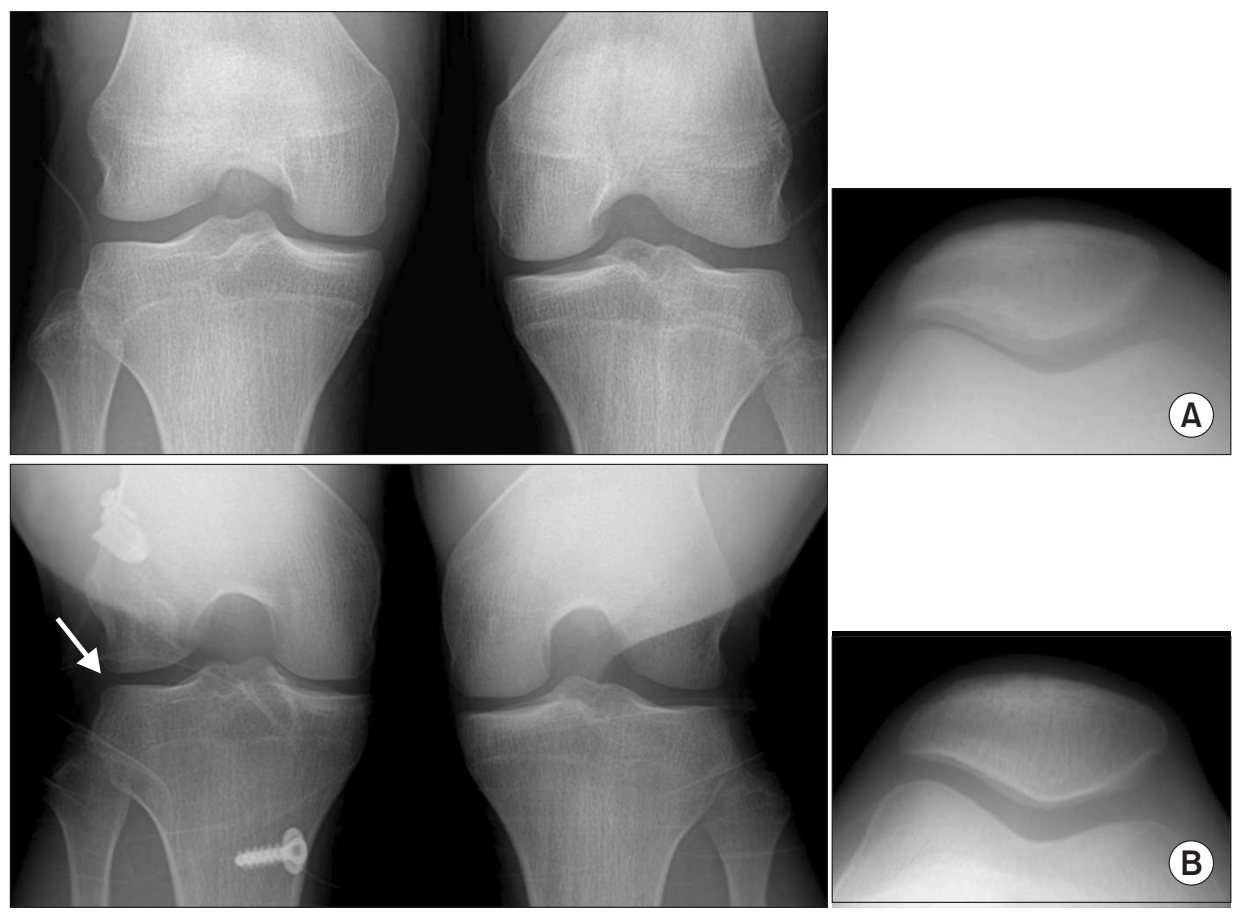

Fig. 2. A 17-year-old male underwent double-bundle anterior cruciate ligament reconstruction with lateral meniscus subtotal meniscectomy. (A) Preoperative Xray showed no degenerative change. (B) Last follow-up X-ray revealed International Knee Documentation Committee grade B degenerative change in the lateral compartment (arrow).

tients $(23.1 \%)$ who were older than 43.1 years of age and 2 of 49 patients (4.1\%) who were younger than 43.1 years of age had degenerative arthritic changes at the last follow-up, showing significant difference between groups $(\mathrm{p}=0.018)$. Four of 8 patients $(50.0 \%)$ with subtotal or total meniscectomy and 4 of 67 patients $(6.0 \%)$ without subtotal or total meniscectomy had degenerative arthritic changes at the last follow-up, showing significant difference between groups ( $\mathrm{p}=0.003$ ). There was no significant difference in the appearance of degenerative arthritic changes between groups divided according to time from injury to surgery, accompanying ligament injury, meniscus repair, and partial men- iscectomy (Table 4).

\section{Return to Sports Activity}

The Tegner activity score was not restored at the short-term follow-up ( $<<0.001)$, but was restored at the last follow-up ( $\mathrm{p}=0.833$ ) (Fig. 3). Significant difference was also observed between the short-term and the last follow-up period $(\mathrm{p}<0.001)$. At the last follow-up, 46 of 67 patients (68.7\%) returned to pre-injury sports based on the Tegner activity score. Cincinnati sports activity scale score was not restored at the short-term follow-up $(\mathrm{p}<0.001)$, but it was restored at the last follow-up $(\mathrm{p}=0.125)$ (Fig. 3). Significant 
Table 4. Relationship between Development of Osteoarthritis (OA) and Factors at Last Follow-up

\begin{tabular}{|c|c|c|c|c|c|}
\hline \multirow{2}{*}{ Variable } & \multicolumn{2}{|c|}{ OA } & \multirow{2}{*}{ p-value ${ }^{a)}$} & \multirow{2}{*}{ Odds ratio } & \multirow{2}{*}{ Confidence interval } \\
\hline & + & - & & & \\
\hline \multicolumn{6}{|l|}{ Age (yr) } \\
\hline$>43.1$ & 6 & 20 & \multirow{2}{*}{$0.018^{\mathrm{b})}$} & \multirow{2}{*}{6.900} & \multirow{2}{*}{$1.281-37.178$} \\
\hline$<43.1$ & 2 & 47 & & & \\
\hline \multicolumn{6}{|c|}{ Time from injury to surgery (day) } \\
\hline$<30$ & 3 & 30 & \multirow{2}{*}{0.475} & \multirow{2}{*}{1.852} & \multirow{2}{*}{$0.404-8.491$} \\
\hline$>30$ & 5 & 27 & & & \\
\hline \multicolumn{6}{|l|}{ Associated ligament injury } \\
\hline+ & 5 & 42 & \multirow{2}{*}{1.000} & \multirow{2}{*}{0.992} & \multirow{2}{*}{$0.218-4.511$} \\
\hline- & 3 & 25 & & & \\
\hline \multicolumn{6}{|l|}{ Meniscus repair } \\
\hline+ & 1 & 11 & \multirow{2}{*}{1.000} & \multirow{2}{*}{0.727} & \multirow{2}{*}{$0.081-6.516$} \\
\hline- & 7 & 56 & & & \\
\hline \multicolumn{6}{|l|}{ Partial meniscectomy } \\
\hline+ & 5 & 21 & \multirow{2}{*}{0.117} & \multirow{2}{*}{3.651} & \multirow{2}{*}{$0.797-16.719$} \\
\hline- & 3 & 46 & & & \\
\hline \multicolumn{6}{|c|}{ Subtotal or total meniscectomy } \\
\hline+ & 4 & 4 & \multirow{2}{*}{$0.003^{\mathrm{b})}$} & \multirow{2}{*}{15.750} & \multirow{2}{*}{$2.834-87.539$} \\
\hline- & 4 & 63 & & & \\
\hline
\end{tabular}

${ }^{\text {a) }}$ Fisher's exact test.

${ }^{b)}$ Indicate a significant difference.

Tegner activity score

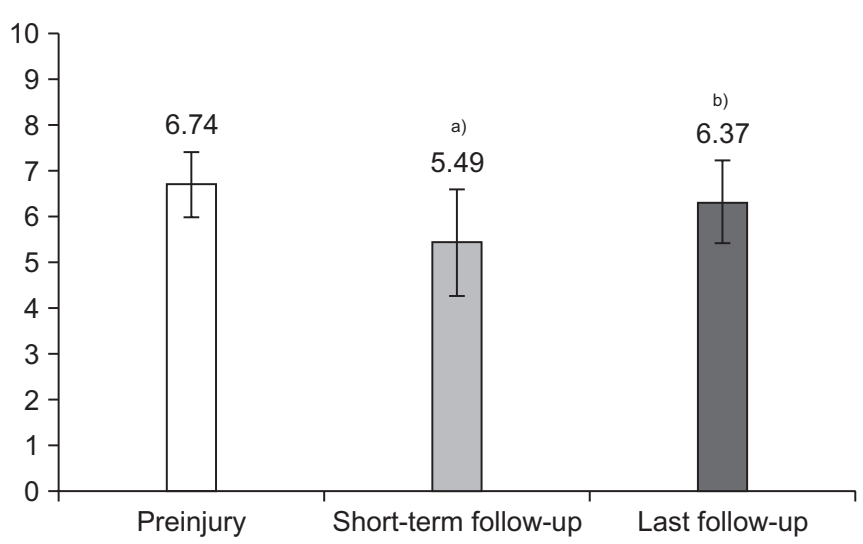

Cincinnati sports activities rating scale

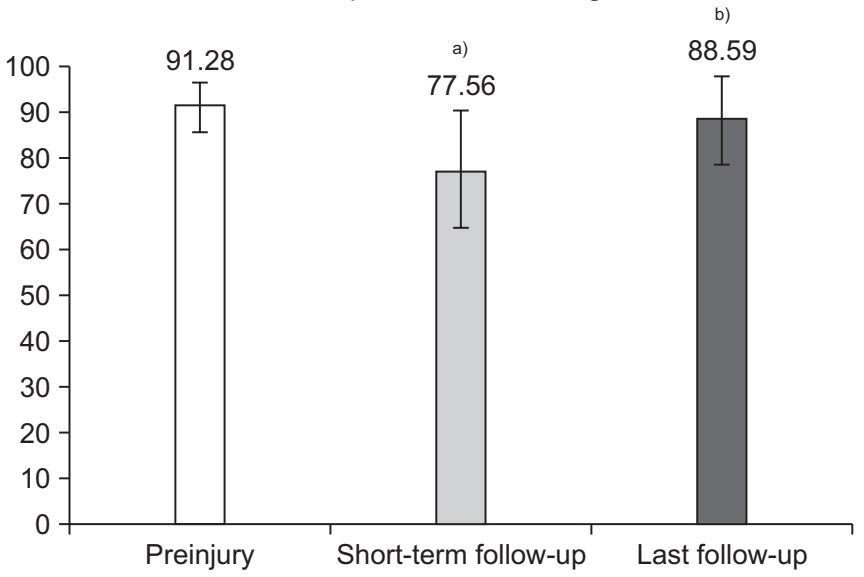

Fig. 3. Sports activity evaluation. ${ }^{\text {a) }}$ Significant difference compared to preinjury. ${ }^{\text {b) }}$ Significant difference compared to short-term follow-up. p-value was determined by Wilcoxon signed ranks test.

difference was also observed between the short-term and the last follow-up period ( $\mathrm{p}<0.001)$. At the last follow-up, 51 of $67 \mathrm{pa}-$ tients $(76.1 \%)$ returned to pre-injury sports activity based on the Cincinnati sports activity scale score.

\section{Discussion}

The principal finding of this study is that double-bundle ACL reconstruction using an outside-in technique showed satisfactory 
results in the aspect of knee function and stability at the two- to six-year follow-up. Only $10.4 \%$ of the patients showed aggravation or development of degenerative changes of greater than IKDC grade A. In addition, $76.7 \%$ of the patients returned to preinjury sports activity according to the Cincinnati sports activity scale.

Single-bundle ACL reconstruction has been associated with not only good clinical outcomes but also degenerative changes and low rates of return to pre-injury sports activity ${ }^{3-7}$. Suomalainen et al. ${ }^{22)}$ recently reported that there was only $5 \%-10 \%$ osteoarthritis during a five-year follow-up after double-bundle ACL reconstruction. Such low incidence of osteoarthritis after double-bundle ACL reconstruction can be explained by the fact that it is more effective for anatomical restoration of normal knee kinematics than single-bundle ACL reconstruction ${ }^{22,23)}$. Lee et al. ${ }^{17)}$ who evaluated the changes of cartilage status after doublebundle ACL reconstruction using a magnetic resonance imaging reported that $68 \%$ had no changes and only $16.8 \%$ showed advancement at 26 -month follow-up. In our study, only $10.4 \%$ of the patients exhibited greater than IKDC grade A degenerative changes. Considering that IKDC grade $\mathrm{C}$ and $\mathrm{D}$ are commonly regarded as indicators of arthritis, the incidence of degeneration among our patients was only $6.0 \%$, similar to that in other studies.

Risk factors for arthritis after ACL reconstruction include sex, age, body mass index, time from injury to surgery, cartilage injury, meniscus injury, ligament injury, and follow-up period ${ }^{24-26)}$. Our study showed no significant difference in degenerative arthritic changes according to time from injury to surgery, accompanying ligament injury, meniscus repair and partial meniscectomy. However, patients who were older than 43.1 years of age showed significant difference in degenerative changes compared to those younger than 43.1 years of age. Dempsey et al. ${ }^{25}$ reported that partial meniscectomy resulted in altered knee joint biomechanics and morphological degeneration was observed in the patellofemoral and femorotibial compartments as patients progressed from surgery. However, Bai et al. ${ }^{24)}$ reported that total meniscectomy increased the contact pressure in the patellofemoral joint, which was not observed in patients with partial meniscectomy. They insisted that total meniscectomy resulted in high contact pressure, which might be the cause of postoperative degenerative arthritis ${ }^{24}$. In our study, we found no significant difference in degenerative changes between the meniscus repair group, partial meniscectomy group, and no meniscal injury group. However, degenerative changes were observed in all of the patients who underwent accompanying subtotal or total menis- cectomy with ACL reconstruction.

The rate of return to pre-injury sports activity was reported as $54 \%-59 \%$ after single-bundle ACL reconstruction ${ }^{27-29)}$. However, $69 \%-72 \%$ of patients returned to pre-injury sports activity after double-bundle ACL reconstruction ${ }^{27,30)}$. In our study, $69.8 \%$ of the patients according to the Tegner activity score and $76.7 \%$ of the patients according to the Cincinnati sports activity scale returned to pre-injury sport activity. However, return to pre-injury sports activity was thought to take longer than one year because there was a difference between the one-year follow-up and the last follow-up on the hop test, a predictor of muscular function, and the mid-thigh circumference, an indicator of muscular volume.

This study includes some limitations. First, there was no control group and the study results were compared only with other previous studies; therefore, further comparative series are necessary. Second, cartilage status was not examined for the evaluation of degenerative changes. Third, the muscular volume and function were not assessed by objective quantification.

\section{Conclusions}

Double-bundle ACL reconstruction using an outside-in technique showed favorable clinical and radiological outcomes in terms of function and stability, degenerative changes, and, especially, return to pre-injury sports activity. However, studies involving comparisons with other techniques and longer follow-up periods are needed to confirm the superiority of this technique.

\section{Conflict of Interest}

No potential conflict of interest relevant to this article was reported.

\section{References}

1. Sajovic M, Strahovnik A, Dernovsek MZ, Skaza K. Quality of life and clinical outcome comparison of semitendinosus and gracilis tendon versus patellar tendon autografts for anterior cruciate ligament reconstruction: an 11-year followup of a randomized controlled trial. Am J Sports Med. 2011; 39:2161-9.

2. Ardern CL, Webster KE, Taylor NF, Feller JA. Return to sport following anterior cruciate ligament reconstruction surgery: a systematic review and meta-analysis of the state of play. $\mathrm{Br} \mathrm{J}$ Sports Med. 2011;45:596-606. 
3. Biau DJ, Tournoux C, Katsahian S, Schranz P, Nizard R. ACL reconstruction: a meta-analysis of functional scores. Clin Orthop Relat Res. 2007;458:180-7.

4. Heming JF, Rand J, Steiner ME. Anatomical limitations of transtibial drilling in anterior cruciate ligament reconstruction. Am J Sports Med. 2007;35:1708-15.

5. Pearle AD, Shannon FJ, Granchi C, Wickiewicz TL, Warren RF. Comparison of 3-dimensional obliquity and anisometric characteristics of anterior cruciate ligament graft positions using surgical navigation. Am J Sports Med. 2008;36:153441.

6. Pombo MW, Shen W, Fu FH. Anatomic double-bundle anterior cruciate ligament reconstruction: where are we today? Arthroscopy. 2008;24:1168-77.

7. Simmons R, Howell SM, Hull ML. Effect of the angle of the femoral and tibial tunnels in the coronal plane and incremental excision of the posterior cruciate ligament on tension of an anterior cruciate ligament graft: an in vitro study. J Bone Joint Surg Am. 2003;85:1018-29.

8. Fithian DC, Paxton EW, Stone ML, Luetzow WF, Csintalan RP, Phelan D, Daniel DM. Prospective trial of a treatment algorithm for the management of the anterior cruciate ligament-injured knee. Am J Sports Med. 2005;33:335-46.

9. Jonsson H, Riklund-Ahlström K, Lind J. Positive pivot shift after ACL reconstruction predicts later osteoarthrosis: 63 patients followed 5-9 years after surgery. Acta Orthop Scand. 2004;75:594-9.

10. Ristanis S, Stergiou N, Siarava E, Ntoulia A, Mitsionis G, Georgoulis AD. Effect of femoral tunnel placement for reconstruction of the anterior cruciate ligament on tibial rotation. J Bone Joint Surg Am. 2009;91:2151-8.

11. Tashman S, Collon D, Anderson K, Kolowich P, Anderst W. Abnormal rotational knee motion during running after anterior cruciate ligament reconstruction. Am J Sports Med. 2004;32:975-83.

12. Aglietti P, Giron F, Cuomo P, Losco M, Mondanelli N. Single-and double-incision double-bundle ACL reconstruction. Clin Orthop Relat Res. 2007;454:108-13.

13. Forsythe B, Kopf S, Wong AK, Martins CA, Anderst W, Tashman S, Fu FH. The location of femoral and tibial tunnels in anatomic double-bundle anterior cruciate ligament reconstruction analyzed by three-dimensional computed tomography models. J Bone Joint Surg Am. 2010;92:1418-26.

14. Yasuda K, Kondo E, Ichiyama H, Tanabe Y, Tohyama H. Clinical evaluation of anatomic double-bundle anterior cruciate ligament reconstruction procedure using hamstring tendon grafts: comparisons among 3 different procedures. Arthroscopy. 2006;22:240-51.

15. Jepsen CF, Lundberg-Jensen AK, Faunoe P. Does the position of the femoral tunnel affect the laxity or clinical outcome of the anterior cruciate ligament-reconstructed knee? A clinical, prospective, randomized, double-blind study. Arthroscopy. 2007;23:1326-33.

16. Pinczewski LA, Salmon LJ, Jackson WF, von Bormann RB, Haslam PG, Tashiro S. Radiological landmarks for placement of the tunnels in single-bundle reconstruction of the anterior cruciate ligament. J Bone Joint Surg Br. 2008;90:172-9.

17. Lee YS, Jeong YM, Sim JA, Kwak JH, Kim KH, Nam SW, Lee BK. Specific compartmental analysis of cartilage status in double-bundle ACL reconstruction patients: a comparative study using pre- and postoperative MR images. Knee Surg Sports Traumatol Arthrosc. 2013;21:702-7.

18. Lee YS, Lee SW, Nam SW, Oh WS, Sim JA, Kwak JH, Lee BK. Analysis of tunnel widening after double-bundle ACL reconstruction. Knee Surg Sports Traumatol Arthrosc. 2012; 20:2243-50.

19. Hefti F, Muller W, Jakob RP, Staubli HU. Evaluation of knee ligament injuries with the IKDC form. Knee Surg Sports Traumatol Arthrosc. 1993;1:226-34.

20. Tegner Y, Lysholm J. Rating systems in the evaluation of knee ligament injuries. Clin Orthop Relat Res. 1985;(198):43-9.

21. Noyes FR, Barber SD, Mooar LA. A rationale for assessing sports activity levels and limitations in knee disorders. Clin Orthop Relat Res. 1989;(246):238-49.

22. Suomalainen P, Jarvela T, Paakkala A, Kannus P, Jarvinen M. Double-bundle versus single-bundle anterior cruciate ligament reconstruction: a prospective randomized study with 5-year results. Am J Sports Med. 2012;40:1511-8.

23. Lee YS, Sim JA, Kwak JH, Nam SW, Kim KH, Lee BK. Comparative analysis of femoral tunnels between outside-in and transtibial double-bundle anterior cruciate ligament reconstruction: a 3-dimensional computed tomography study. Arthroscopy. 2012;28:1417-23.

24. Bai B, Shun H, Yin ZX, Liao ZW, Chen N. Changes of contact pressure and area in patellofemoral joint after different meniscectomies. Int Orthop. 2012;36:987-91.

25. Dempsey AR, Wang Y, Thorlund JB, Mills PM, Wrigley TV, Bennell KL, Metcalf BR, Hanna F, Cicuttini FM, Lloyd DG. The relationship between patellofemoral and tibiofemoral morphology and gait biomechanics following arthroscopic partial medial meniscectomy. Knee Surg Sports Traumatol Arthrosc. 2013;21:1097-103. 
26. Li RT, Lorenz S, Xu Y, Harner CD, Fu FH, Irrgang JJ. Predictors of radiographic knee osteoarthritis after anterior cruciate ligament reconstruction. Am J Sports Med. 2011;39: 2595-603.

27. Aglietti P, Giron F, Losco M, Cuomo P, Ciardullo A, Mondanelli N. Comparison between single-and double-bundle anterior cruciate ligament reconstruction: a prospective, randomized, single-blinded clinical trial. Am J Sports Med. 2010;38:25-34.

28. Keays SL, Bullock-Saxton JE, Keays AC, Newcombe PA, Bullock MI. A 6-year follow-up of the effect of graft site on strength, stability, range of motion, function, and joint de- generation after anterior cruciate ligament reconstruction: patellar tendon versus semitendinosus and Gracilis tendon graft. Am J Sports Med. 2007;35:729-39.

29. Roe J, Pinczewski LA, Russell VJ, Salmon LJ, Kawamata T, Chew M. A 7-year follow-up of patellar tendon and hamstring tendon grafts for arthroscopic anterior cruciate ligament reconstruction: differences and similarities. Am J Sports Med. 2005;33:1337-45.

30. Shen W, Jordan S, Fu F. Review article: anatomic double bundle anterior cruciate ligament reconstruction. J Orthop Surg (Hong Kong). 2007;15:216-21. 